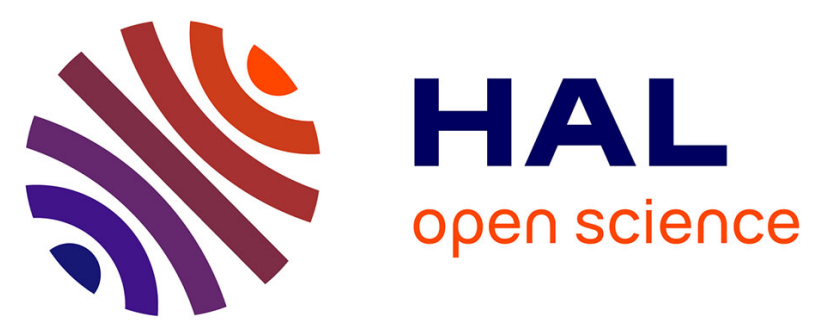

\title{
A 100-Gb/s, 1-tap Feed-forward based Analog Equalizer for Optical Communication Applications
}

\author{
Ronan Mettetal, Jean-Yves Dupuy, Filipe Jorge, Muriel Riet, Virginie \\ Nodjiadjim, Agnieszka Konczykowska, Achour Ouslimani
}

\section{- To cite this version:}

Ronan Mettetal, Jean-Yves Dupuy, Filipe Jorge, Muriel Riet, Virginie Nodjiadjim, et al.. A 100-Gb/s, 1-tap Feed-forward based Analog Equalizer for Optical Communication Applications. International Microwave Symposium (IMS), May 2016, San Francisco, United States. 10.1109/MWSYM.2016.7540048 . hal-01280141

\section{HAL Id: hal-01280141 https://hal.science/hal-01280141}

Submitted on 2 Mar 2016

HAL is a multi-disciplinary open access archive for the deposit and dissemination of scientific research documents, whether they are published or not. The documents may come from teaching and research institutions in France or abroad, or from public or private research centers.
L'archive ouverte pluridisciplinaire HAL, est destinée au dépôt et à la diffusion de documents scientifiques de niveau recherche, publiés ou non, émanant des établissements d'enseignement et de recherche français ou étrangers, des laboratoires publics ou privés. 


\title{
A 100-Gb/s, 1-tap Feed-forward based Analog Equalizer for Optical Communication Applications
}

\author{
Ronan Mettetal $^{*, \dagger}$, Jean-Yves Dupuy ${ }^{\dagger}$, Filipe Jorge ${ }^{\dagger}$, Muriel Riet $^{\dagger}$, Virginie Nodjiadjim ${ }^{\dagger}$, \\ Agnieszka Konczykowska ${ }^{\dagger}$ and Achour Ouslimani* \\ ${ }^{*}$ Quartz Laboratory, ENSEA \\ 6, Avenue du Ponceau, 95014 Cergy, FRANCE \\ Email: ronan.mettetal@ensea.fr \\ †III-V Lab, a joint lab between 'Alcatel-Lucent Bell Labs France', 'Thales Research and Technology' and 'CEA Leti', \\ 1, Avenue Augustin Fresnel, 91767 Palaiseau, FRANCE
}

\begin{abstract}
This paper reports the design and measurement results of a 1-tap feed-forward based analog equalizer, mainly designed with differential pair amplifier cells composed of Indium Phosphide (InP) heterojunction bipolar transistors. This analog equalizer exhibits a maximal peaking frequency and amplitude of $50 \mathrm{GHz}$ and $12 \mathrm{~dB}$ respectively. Large signal measurements demonstrated an equalization at $100 \mathrm{~Gb} / \mathrm{s}$ of a $3 \mathrm{~m}$-long $1.85-\mathrm{mm}$ connector coaxial cable, which represents a lossy channel of $20 \mathrm{~dB}$ at $50 \mathrm{GHz}$. To the authors' knowledge, this is the first analog equalizer reported with an equalization capability demonstrated at $100 \mathrm{~Gb} / \mathrm{s}$.

Index Terms-Analog electronics, feed-forward equalizer, InP DHBT, equalization.
\end{abstract}

\section{INTRODUCTION}

With the continuous growth of global IP traffic, new methods are constantly developed in order to increase optical communications channel capacity [1]. From a standard of $25 \mathrm{~Gb} / \mathrm{s}$ a few years ago, we are progressively reaching data rates of $100 \mathrm{~Gb} / \mathrm{s}$ with an OOK modulation format in one single wavelength, mainly for short reach applications. These high data rate transceivers become difficult to implement because of electro-optical components bandwidth limitation [2]. Forward error correction (FEC) is commonly used in order to overcome these limitations but it needs data rate overhead and it also requires important power consumption as well as complex algorithms [3].

Nowadays, many solutions have been tried to increase optical communication data rate while relaxing receiver complexity. One of the main low-cost solutions remains analog equalization. Indeed, this technique can increase the overall channel bandwidth in order to reduce intersymbol interference (ISI) thus getting a correct bit error rate at the reception.

Figure 1 illustrates the principle of this well-known technique. An analog equalizer is used to set a peaking at high frequency in its own frequency response. By cascading this analog equalizer with a limited bandwidth system, we increase the total bandwidth, thus allowing a data rate increase [4].

A lot of very high speed analog equalizers have been reported through last years, but no one have been adressed the $100-\mathrm{GHz}$ class bandwidth which is considered here. In [5], authors reported a 90-Gb/s 2:1 multiplexer with a 1-tap feedforward equalizer (FFE) in SiGe HBT technology, capable of

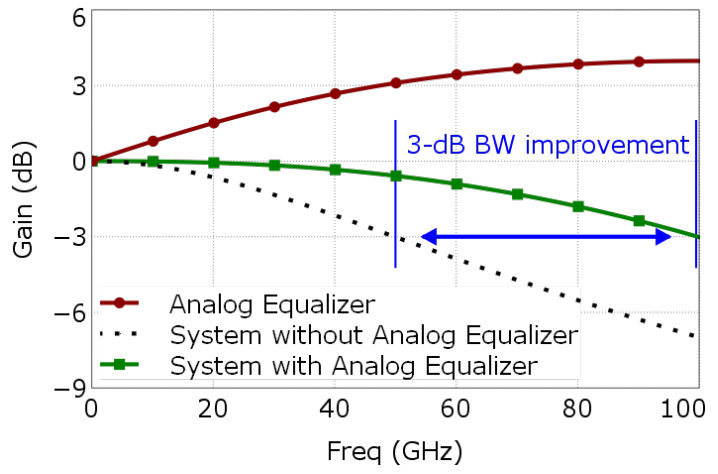

Fig. 1. Overall frequency response of a limited bandwidth system cascaded with an analog equalizer

equalizing a 90-Gb/s NRZ signal with a channel loss of $12 \mathrm{~dB}$ at $45 \mathrm{GHz}$. Here, we report a 1-tap FFE capable of equalizing a $100-\mathrm{Gb} / \mathrm{s}$ NRZ signal with a channel loss of $20 \mathrm{~dB}$ at $50 \mathrm{GHz}$.

This paper is organized as follows. In the first part, we present the design of our analog equalizer. The second part deals with the chip fabrication and the last part reports our $\mathrm{S}$-parameters and large signal measurement results.

\section{DESIGN}

Our analog equalizer is a 1-tap FFE based architecture designed with InP double heterojunction bipolar transistors (DHBTs). This technology provides high $\mathrm{f}_{\mathrm{T}} / \mathrm{f}_{\max }$ as well as a large breakdown voltage.

Figure 2 presents the schematic of our analog equalizer. It is composed of input and output buffers and a 1-tap FFE composed of a main stage which is biased by a DC supply $\mathrm{V}_{\alpha}$ and a 1-tap stage composed of a delay and a variable gain amplifier whose gain is tunable with the DC supply $\mathrm{V}_{\beta}$.

The input buffer is a differential pair amplifier cell degenerated by a resistor-capacity couple in order to enhance the bandwidth as well as the linearity. This input buffer is broadband impedance matched with the $50-\Omega$ input emitterfollower. The main stage $\alpha$ follows the same architecture, but some passive components values differ because of adaptation impedances between stages. 


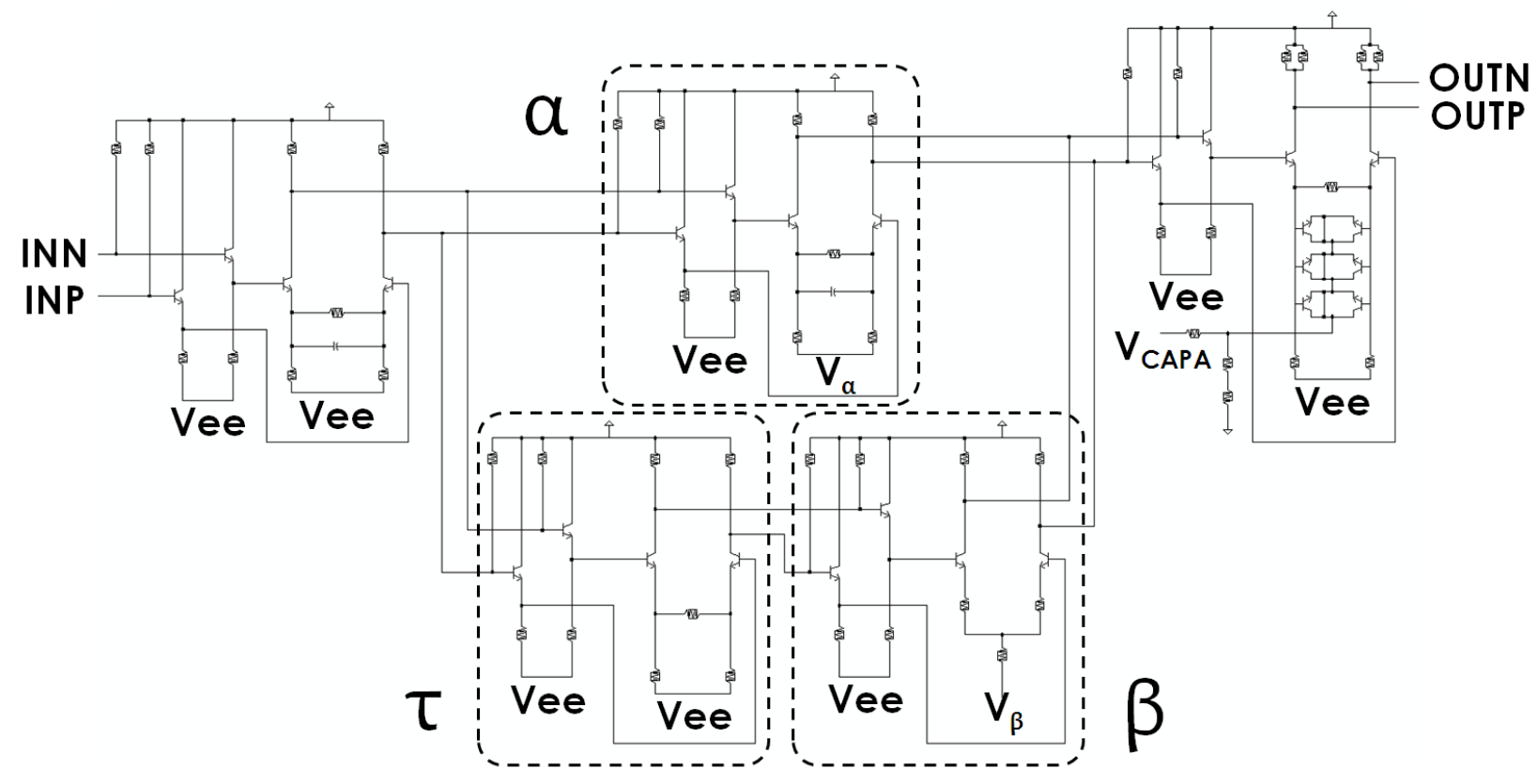

Fig. 2. Schematic of the 1-tap feed-forward based analog equalizer

As for the 1-tap stage, it is composed of a large bandwidth differential pair amplifier cell acting as a delay while providing a large bandwidth and a high linearity $(\tau)$, and a variable gain amplifier which is also a differential pair amplifier cell but with very low degenerative resistor values, in order to tune the gain of this amplifier with an independent DC supply $\left(\mathrm{V}_{\beta}\right)$.

Finally, the output buffer is a large bandwidth tunable analog equalizer based on a differential pair amplifier cell. This architecture has already been reported in [6]. This output buffer can provide a boost with variable peaking frequencies thanks to the differential pair degeneration made by a couple resistor-varactor. The capacitive value of the varactor is tunable thanks to $V_{\text {CAPA }}$. It can be useful for our application because a 1-tap FFE can only have one peaking frequency [7]. The parallel 100- $\Omega$ collector resistors of the output buffer ensure the broadband output impedance matching.

\section{FABRICATION}

Our circuit has been fabricated thanks to InP DHBTs providing a $\mathrm{f}_{\mathrm{T}} / \mathrm{f}_{\max }$ of $270 / 420 \mathrm{GHz}$ and a breakdown voltage larger than $6 \mathrm{~V}$ [8]. The process also provides 3 levels of metalization, $\mathrm{NiCr}$ resistors and $\mathrm{MiM}$ capacitors. Figure 3 shows the fabricated chip whose size is $3.6 \times 1.5 \mathrm{~mm}^{2}$. The core of the circuit occupies an area of $0.43 \mathrm{~mm}^{2}$. Its power consumption is around $660 \mathrm{~mW}$, depending on the equalization settings. The value of Vee is $-3.5 \mathrm{~V}$.

\section{Measurement Results}

\section{A. S-parameters measurements}

We performed S-parameters measurements with an Anritsu Vector Star from $100 \mathrm{MHz}$ up to $110 \mathrm{GHz}$. The test bench is composed of bias-T, 1.85-mm-connector coaxial cables and probes. Figure 4 presents the measurement results of the mixed mode differential gain $S_{21}\left(S_{d d 21}\right)$ [9] for different values of $\mathrm{V}_{\beta}$ and $\mathrm{V}_{\mathrm{CAPA}}$ and the input and output reflection coefficients. Due to the differential aspect of our 1-tap FFE, there are two input and output reflection coefficients presented. These parameters do not show a variation with the different possible settings of the analog equalizer.

As mentioned in the abstract, we get a maximal differential peaking of $12 \mathrm{~dB}$ at $50 \mathrm{GHz}$ by properly adjusting the tuning parameters. We have a minimal DC gain of $-9 \mathrm{~dB}$ as well as a maximal peak gain of $+5.5 \mathrm{~dB}$. The input and output reflection coefficients are lower than $-10 \mathrm{~dB}$ up to $70 \mathrm{GHz}$ for both of them. The tuning parameters allows us to have a tunable peaking frequency between 30 and $50 \mathrm{GHz}$. The peaking amplitude can also be tuned between 0 and $12 \mathrm{~dB}$.

\section{B. Equalization performance}

The first step of large signal measurement experiments consists of feding our analog equalizer at one input with a $100-\mathrm{Gb} / \mathrm{s}$ NRZ signal provided by a SHF 50-Gb/s $2^{15}-1$ PRBS source followed by an in-house 2:1 selector. The eye amplitude

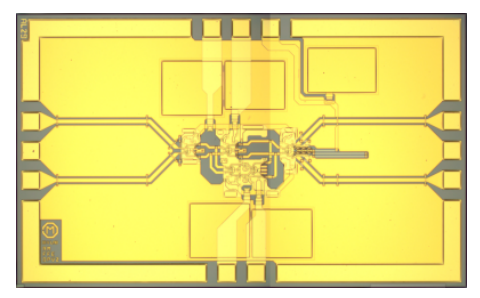

Fig. 3. Microphotograph of the fabricated chip. Chip size is $3.6 \times 1.5 \mathrm{~mm}^{2}$ and the core of the circuit occupies an area of $0.43 \mathrm{~mm}^{2}$ 


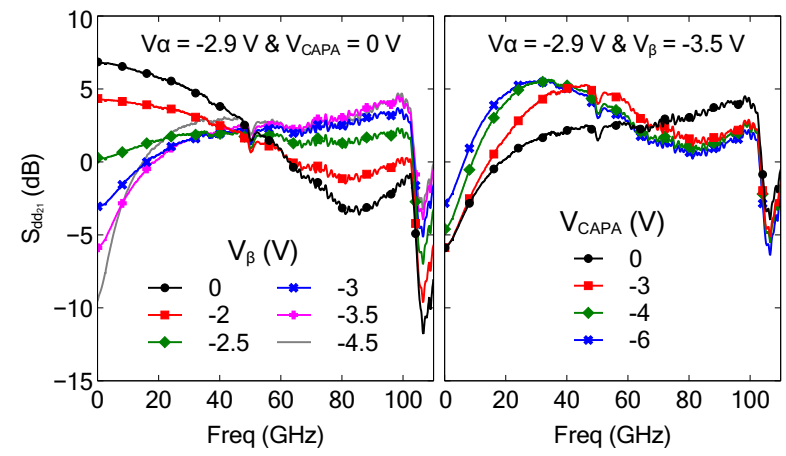

(a)

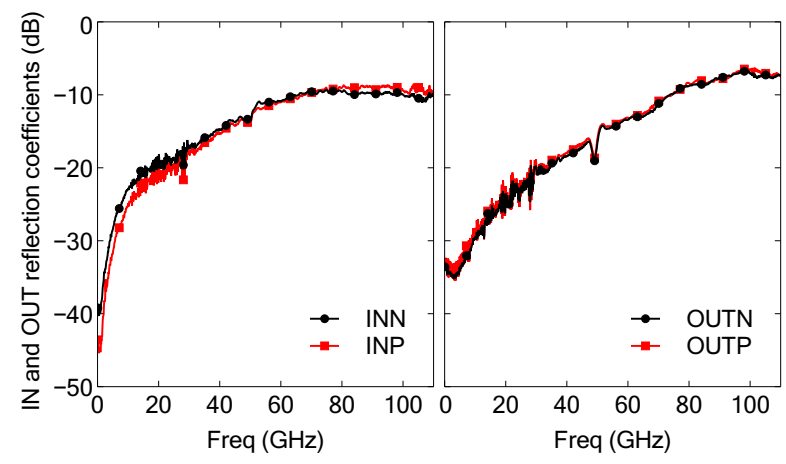

(b)

Fig. 4. S-parameters measurements results for $\mathrm{V}_{\alpha}=-2.9 \mathrm{~V}$ and for differents values of $\mathrm{V}_{\beta}$ and $\mathrm{V}_{\mathrm{CAPA}}$

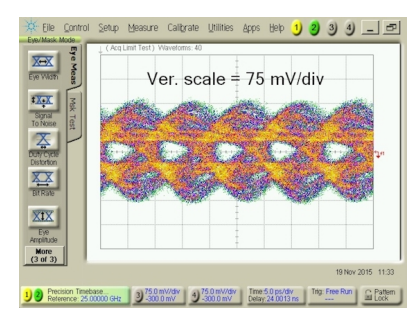

(a) $\mathrm{V}_{\beta}=-4.5 \mathrm{~V}$ and $\mathrm{V}_{\mathrm{CAPA}}=0 \mathrm{~V}$

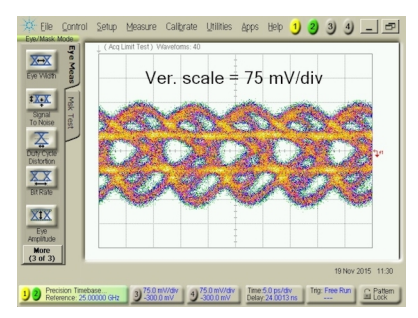

(b) $\mathrm{V}_{\beta}=-3.5 \mathrm{~V}$ and $\mathrm{V}_{\mathrm{CAPA}}=-3 \mathrm{~V}$
Fig. 5. Eye diagrams for the differential output of the analog equalizer at $100-\mathrm{Gb} / \mathrm{s}$ for $\mathrm{V}_{\alpha}=-2.9 \mathrm{~V}$ and for differents values of $\mathrm{V}_{\beta}$ and $\mathrm{V}_{\text {CAPA }}$. Visible overshoots are synonyms of pre-emphasis, which is a well-know equalization effect

is around $300 \mathrm{mV}_{\mathrm{pp}}$. The other input is connected to a $\mathrm{DC}$ supply whose value is the mean value of the PRBS signal. Figure 5 illustrates different eye diagrams measured at the differential output of the analog equalizer for different values of $\mathrm{V}_{\beta}$ and $\mathrm{V}_{\mathrm{CAPA}}$. The equalization effect is well identified with the visible desired overshoots synonym of pre-emphasis.

In order to demonstrate the equalization performance of our analog equalizer, we filtered the $100-\mathrm{Gb} / \mathrm{s}$ PRBS signal with a $1.85-\mathrm{mm}$-connector coaxial cable. The synoptic of the measurement test bench is illustrated in figure 6. It is composed of the same $2^{16}-1$ PRBS source at $100-\mathrm{Gb} / \mathrm{s}$ but in this case filtered by a $3 \mathrm{~m}$-long 1.85 -mm-connector coaxial cable, whose frequency response is presented in figure 7(a). This figure also presents the calculated frequency response of

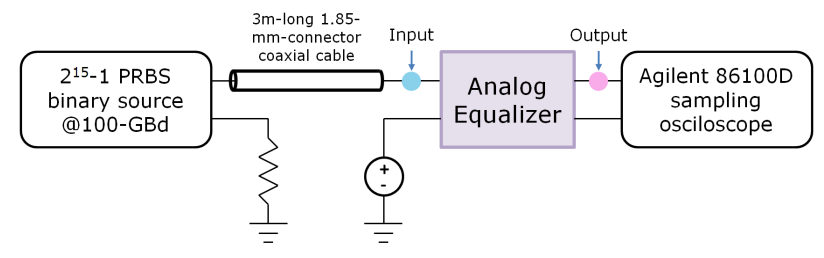

Fig. 6. Synoptic of the transient measurement bench

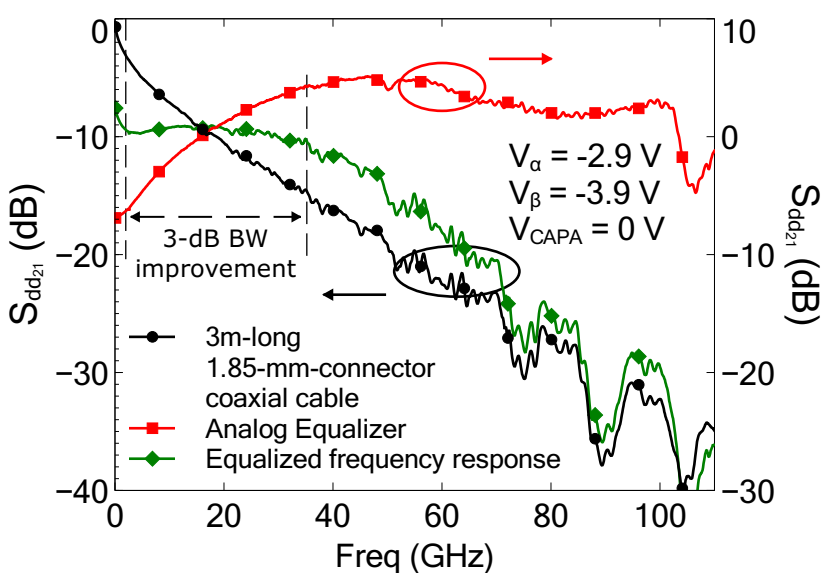

(a) S-parameters measurements of 3m-long 1.85-mm-connector coaxial cable $S_{21}$ and the calculated frequency response of the equalized channel

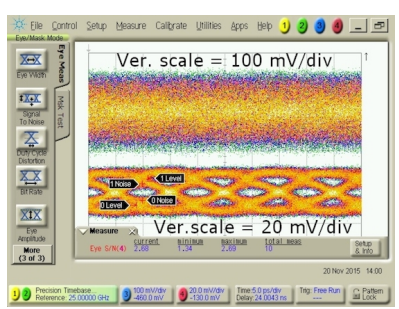

(b) $($ Hor. scale $=5 \mathrm{ps} / \mathrm{div})$

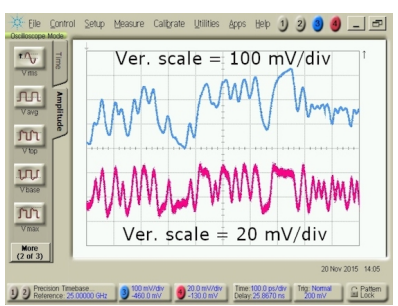

(c) (Hor. scale $=100 \mathrm{ps} / \mathrm{div})$
Fig. 7. Equalization performance at $100-\mathrm{Gb} / \mathrm{s}$. (b) and (c) present $100-\mathrm{Gb} / \mathrm{s}$ input signal filtered by a $3 \mathrm{~m}$-long 1.85 -mm-connector coaxial cable (top) and equalized output (bottom) eye diagrams and waveforms, respectively

the equalized channel composed of this coaxial cable and our analog equalizer with the appropriate settings. We get a 3-dB bandwidth of $35 \mathrm{GHz}$ instead of almost $2 \mathrm{GHz}$ thanks to our analog equalizer.

Figure 7(b) and 7(c) presents the results of this measurement. We obtained an opened $100-\mathrm{Gb} / \mathrm{s}$ eye diagram with a measured $\mathrm{Q}$ factor of 2.68 at the analog equalizer output. The associated waveforms illustrate this equalizing effect by clearly reshaping the signal.

Other measurements have been performed with different lower lengths of $1.85-\mathrm{mm}$-connector coaxial cable showing even better performances in terms of $\mathrm{Q}$ factor of the equalized eye diagram at the output of the analog equalizer. Figure 8 illustrates the results for a $2 \mathrm{~m}$-long 1.85 -mm-connector coaxial cable with the same vertical scales than in figure 7 . In that case, we measured a $\mathrm{Q}$ factor of 3.75 at the analog equalizer output. 
TABLE I

CONTINUOUS TIME ANALOG EQUALIZERS STATE-OF-THE-ART

\begin{tabular}{|c|c|c|c|c|c|c|c|}
\hline Parameter & Unit & {$[10]$} & {$[11]$} & [5] & [7] & {$[12]$} & This work \\
\hline Maximal Equalization Data Rate & $\mathrm{Gb} / \mathrm{s}$ & 49 & up to 70 & 90 & 40 & 78.6 & 100 \\
\hline Equalizer type & $*$ & 7-Tap FFE & $\begin{array}{l}\text { Continuous Time } \\
\text { Linear Equalizer }\end{array}$ & 1-Tap FFE & 7-Tap FFE & $\begin{array}{l}\text { Continuous Time } \\
\text { Linear Equalizer }\end{array}$ & 1-Tap FFE \\
\hline Frequency peaking tunability & $*$ & YES & NO & YES & YES & YES & YES \\
\hline Peaking frequency(ies) & $\mathrm{GHz}$ & $*$ & 52 & $*$ & $*$ & 5 up to 57 & 30 up to 50 \\
\hline Equalization & $\mathrm{dB}$ & $9 @ 25 \mathrm{GHz}^{1}$ & $31 @ 52 \mathrm{GHz}$ & $12 @ 45 \mathrm{GHz}^{1}$ & $9 @ 20 \mathrm{GHz}^{1}$ & $40 @ 57 \mathrm{GHz}$ & $12 @ 50 \mathrm{GHz}$ \\
\hline Power Supply & $\mathrm{V}$ & 5 & 3.3 & 3.6 & 1 & 1.8 & $-3.5, \mathrm{~V}_{\alpha}, \mathrm{V}_{\beta}, \mathrm{V}_{\mathrm{CAPA}}$ \\
\hline Max. Power Consumption & $\mathrm{mW}$ & 750 & 336.6 & 1940 & 80 & 250 & 660 \\
\hline Chip area & $\mathrm{mm}^{2}$ & $1 \times 2$ & $0.99 \times 0.895$ & $1.66 \times 1.66$ & $2 \times 2$ & $0.71 \times 1.03$ & $3.6 \times 1.5$ \\
\hline Process node & $*$ & $0.18 \mu \mathrm{m}$ & $0.13 \mu \mathrm{m}$ & $0.13 \mu \mathrm{m}$ & $65 \mathrm{~nm}$ & $0.13 \mu \mathrm{m}$ & $0.7 \mu \mathrm{m}$ \\
\hline Material & * & $\mathrm{SiGe}$ & $\mathrm{SiGe}$ & $\mathrm{SiGe}$ & $\mathrm{Si}$ & $\mathrm{SiGe}$ & $\operatorname{InP}$ \\
\hline Transistor & * & BiCMOS & BiCMOS & HBT & CMOS & BiCMOS & DHBT \\
\hline $\mathrm{f}_{\mathrm{T}}$ & $\mathrm{GHz}$ & 160 & 230 & 210 & * & 230 & 270 \\
\hline $\mathrm{f}_{\max }$ & $\mathrm{GHz}$ & 160 & 280 & 260 & * & 280 & 420 \\
\hline
\end{tabular}

${ }^{1}$ Equalized cable loss reported by measurements at Nyquist frequency

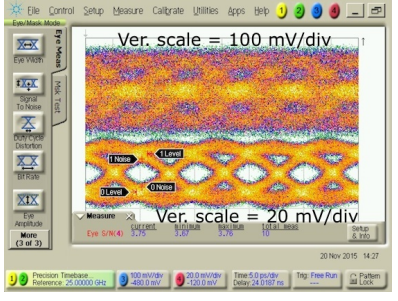

(a) (Hor. scale $=5 \mathrm{ps} / \mathrm{div}$ )

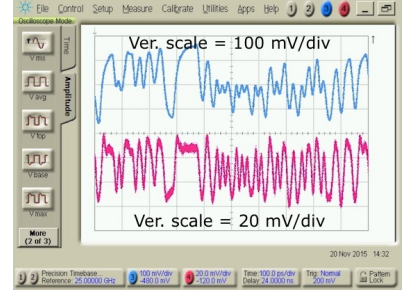

(b) $($ Hor. scale $=100 \mathrm{ps} / \mathrm{div})$

Fig. 8. Equalization performance at 100-Gb/s. (b) and (c) present 100-Gb/s input signal filtered by a $2 \mathrm{~m}$-long 1.85 -mm-connector coaxial cable (top) and equalized output (bottom) eye diagrams and waveforms, respectively

\section{CONCLUSiON}

An analog equalizer with a 1-tap FFE architecture and designed with InP DHBTs is reported. We measured a tunable peaking from 0 to $12 \mathrm{~dB}$ in a frequency range between 30 and $50 \mathrm{GHz}$. Large signal measurement were conducted and we performed an equalization at $100-\mathrm{Gb} / \mathrm{s}$ for a $3 \mathrm{~m}$-long 1.85 mm-connector coaxial cable with a loss of $20 \mathrm{~dB}$ at $50 \mathrm{GHz}$. As demonstrated, the tunability of our analog equalizer makes it efficient to equalize various lengths of 1.85 -mm-connector coaxial cable. The table I presents the different parameters and results of the best analog equalizers reported to date. Our 1tap feed-forward based analog equalizer demonstrates a good peaking performance as well as the highest equalized data rate.

\section{ACKNOWLEDGMENT}

The authors want to thank Hervé Aubry, III-V Lab, for process, Olivier Drisse and Estelle Derouin, III-V Lab, for e-beam lithography and Benjamin Saturnin for epitaxy.

\section{REFERENCES}

[1] S. Bigo, "Coherent Optical long-haul System Design," Optical Fiber Conference, OSA Technical Digest, paper OTh3A.1, May 2012.

[2] A. Chraplyvy, "Plenary Paper: The coming capacity crunch," in Proc. of the $35^{\text {th }}$ European Conference on Optical Communication, 20-24 Sept. 2009.

[3] George C. Clark, Jr. and J. Bibb Cain, Error-Correction Coding for Digital Communications, New York: Plenum Press, 1981.

[4] E. Säckinger, Broadband Circuits for Optical Fiber Communication, Wiley, April 2005.

[5] E. Laskin and A. Rylyakov, "A 90-Gb/s 2:1 Multiplexer with 1-Tap FFE in SiGe Technology," in Proc. Compound Semiconductor Integrated Circuits Symposium (CSICS), 12-15 Oct. 2008.

[6] R. Mettetal, J.-Y. Dupuy, A. Ouslimani and J. Godin, "Large bandwidth tunable analog equalizers based on an InP DHBT differential pair amplifier cell for 100 -GBaud communication systems," $10^{\text {th }}$ Conference on Ph.D. Research in Microelectronics and Electronics (PRIME), 2014.

[7] A. Momtaz and M. M. Green, "An $80 \mathrm{~mW} 40 \mathrm{~Gb} / \mathrm{s}$ 7-Tap T/2-Spaced Feed-Forward Equalizer in $65 \mathrm{~nm}$ CMOS," IEEE Journal of Solid-State Circuits, vol. 45, no. 3, pp. 629-639, March 2010.

[8] V. Midili, V. Nodjiadjim, T. K. Johansen, M. Riet, J.-Y. Dupuy, A. Konczykowska and M. Squartecchia, "Electrical and thermal characterization of single and multi-finger InP DHBTs," Microwave Integrated Circuits Conference (EuMIC), 10 ${ }^{\text {th }}$ conference, pp. 148-151, 7-8 Sept. 2015.

[9] W. Fan, A. C. W. Lu, L. L. Wai and B. K. Lok, "Mixed-mode Sparameter characterization of differential structures," Electronics Packaging Technology, $5^{\text {th }}$ conference, pp. 537-553, 2003.

[10] A. Hazneci and S. P. Voinigescu, "A 49-Gb/s, 7-tap transversal filter in $0.18-\mu \mathrm{m}$ SiGe BiCMOS for backplane equalization," in Proc. IEEE Compound Semiconductor Integrated Circuit Symposium, Monterey, CA, Oct. 2004, pp. 101-104.

[11] A. Balteanu and S. P. Voinigescu, "A cable equalizer with $31 \mathrm{~dB}$ of adjustable peaking at $52 \mathrm{GHz}$, Proc. IEEE Bipolar/BiCMOS Circuits and Technology Meeting, 12-14 Oct. 2009, pp. 154-157.

[12] I. Sarkas, S. P. Voinigescu, ”A 1.8 V SiGe BiCMOS Cable Equalizer with 40-dB Peaking Control up to $60 \mathrm{GHz}$," in Proc. IEEE Compound Semiconductor Integrated Circuit Symposium, La Jolla, CA, Oct. 2012, pp. 1-4. 